corrigendum

\title{
A mouse model for the learning and memory deficits associated with neurofibromatosis type I
}

A J Silva, P W Frankland, Z Marowitz, E Friedman, G Lazlo, D Cioffi, T Jacks \& R Bourtchuladze

Nature Genet. 15, 281-284 (1997).

The name of the fifth author is incomplete and misspelled: G Lazlo is GS Laszlo.

erratum

nagie oko, encoding a MAGUK-family protein, is essential for cellular patterning of the retina

Wei, X \& Malicki, J

Nature Genet. 31, 150-157 (2002).

GenBank accession numbers for the new genes reported in this article were erroneously omitted. They are AF510111 for nok and AF509629 for xwjm1. 